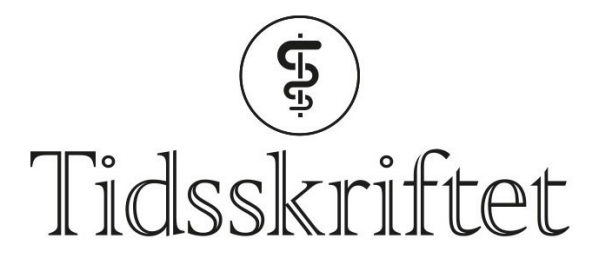

DEN NORSKE LEGEFORENING

\title{
Helseeffekter av amming
}

KRONIKK

\section{KETIL STØRDAL}

E-post: ketil.stordal@fhi.no

Ketil Størdal (f. 1966) er ph.d., spesialist i barnesykdommer, seniorforsker ved Folkehelseinstituttet og overlege ved Barne- og ungdomsklinikken, Sykehuset Østfold.

Forfatter har fylt ut ICMJE-skjemaet og oppgir ingen interessekonflikter.

\section{NICOLAI ANDRÉ LUND-BLIX}

Nicolai André Lund-Blix (f. 1982) er ph.d. og klinisk ernæringsfysiolog ved Folkehelseinstituttet og Barne- og ungdomsklinikken, Oslo universitetssykehus.

Forfatter har fylt ut ICMJE-skjemaet og oppgir ingen interessekonflikter.

\section{LARS CHRISTIAN STENE}

Lars Christian Stene (f. 1971) er ph.d., ernæringsfysiolog og seniorforsker ved Folkehelseinstituttet og ved Oslo diabetes forskningssenter, Oslo universitetssykehus.

Forfatter har fylt ut ICMJE-skjemaet og oppgir ingen interessekonflikter.

Få temaer vekker så sterke følelser i medisinske fagmiljø som amming. Hvor gode holdepunkter finnes det for å anbefale morsmelk som eneste ernæring etter de fire første levemånedene?

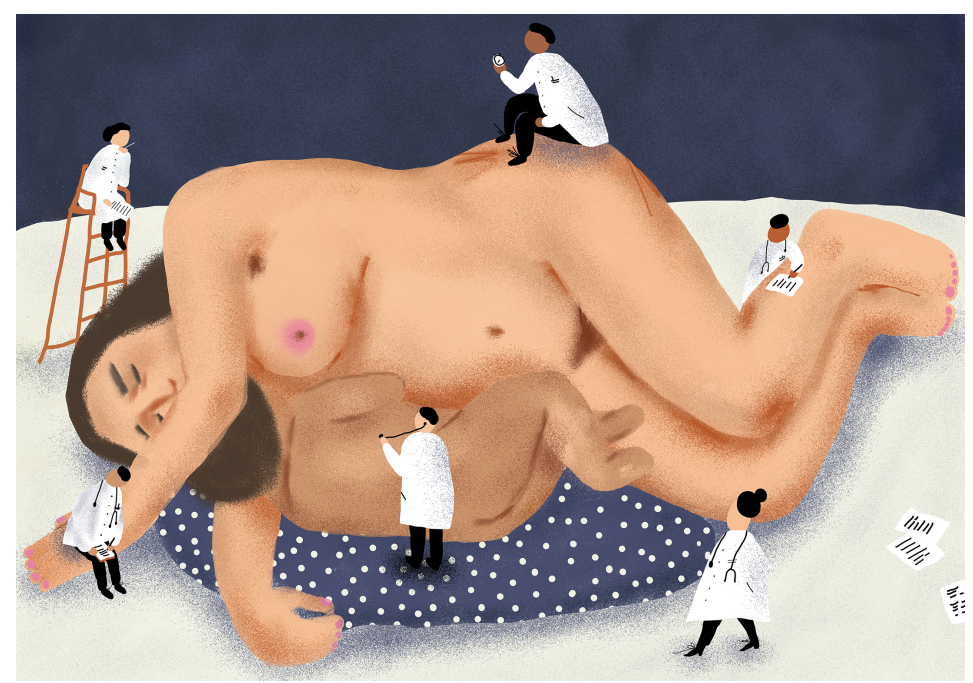

Illustrasjon: Sunniva Sunde Krogseth

I 2001 kom Verdens helseorganisasjon (WHO) med en anbefaling om at spedbarn bør fullammes i seks måneder og at ammingen bør fortsette i 24 måneder. Norske retningslinjer fra samme år anbefaler også fullamming i seks måneder og at barn bør få morsmelk i minst 12 måneder. Reviderte retningslinjer fra 2016 ble i hovedsak uendret, selv om intern 
uenighet førte til mange forbehold omkring tilleggsmat fra fire måneders alder $(1,2)$.

Helsedirektoratets rapporter om spedbarnsernæring (Spedkost) fra 1999, 2006 og 2013 viser at andelen mødre som fullammer ved 5,5 måneders alder har $ø \mathrm{kt}$ noe, fra $12 \%$ til $17 \%$. Andelen som fortsatt ammer når barnet er 12 måneder, har gått litt ned fra 2007 til 2013, og ligger nå på omkring $35 \%$ (3). Et mindretall av norske mødre følger altså Helsedirektoratets retningslinjer.

\section{Forskningsdesign}

I medisinsk årsaksforskning er gullstandarden kontrollerte studier der deltagere tilfeldig blir trukket ut til ulike intervensjoner. Det finnes enkelte studier der spedbarn i tillegg til morsmelk blir randomisert til introduksjon av nye matvarer ved ulike tidspunkt for å studere risiko for fødemiddelreaksjoner (4-6).

På grunn av de veletablerte positive effektene av amming vil det være uetisk å randomisere spedbarn til å få morsmelk eller ikke. Men man kan sammenligne grupper som randomiseres til standard veiledning eller ekstra promotering av amming (7).

Man kan også få nyttig kunnskap om effekter av morsmelk ved å bruke en god nummer to i hierarkiet i kunnskapsgrunnlag/evidens: prospektive kohortstudier der mor og barn selv velger når amming skal avsluttes. Svakheten er at det ikke er en enkelt intervensjon som studeres. Varighet av amming varierer systematisk sammen med andre faktorer. Til en viss grad kan dette korrigeres ved å justere for kjente sammenblandingsfaktorer.

Mer enn 100 ooo barn er med i Den norske mor og barn-unders $\varnothing$ kelsen (MoBa).

Rekrutteringen til denne undersøkelsen fra 1999-2008 ga en viss sosial skjevhet i utvalget, men andelen som følger norske anbefalinger om amming sammenfaller med Spedkost (8). Mødre som ammer lenge i undersøkelsen har signifikant høyere utdanning og alder, røyker mindre og har oftere født vaginalt et barn over $2500 \mathrm{~g}$ til termin (8). Slik henger amming i rike land sammen med andre helsefremmende faktorer, mens det i fattige land gjerne er motsatt (9). Derfor bør studier av helseeffekter av amming ta hensyn til slike sammenblandingsfaktorer (konfundering).

\section{Skjevheter i studiedesign}

Manglende informasjon om sammenblandingsfaktorer er en begrensning ved mange tidligere studier av amming. At barn som ammes lenge får høyere IQ og lavere risiko for overvekt, kan også forklares av at mødrene har høyere utdanning og lavere kroppsmasseindeks. Et søskenflokkdesign der sammenligningen skjer mellom barn med samme mor, kan korrigere for dette (10).

Mange tidligere publiserte studier av amming er pasient-kontroll-studier. Slike studier har større risiko for andre systematiske skjevheter i tillegg til de som finnes i prospektive studier, slik som erindringsskjevhet (recall bias) og seleksjonsskjevhet. Pasient-kontrollstudier er vist å overestimere effekter av amming som ikke har blitt bekreftet i prospektive studier (11-13).

Som for andre helseråd må råd om amming gis på grunnlag av oppsummert kunnskap om alle kjente effekter. Vi har studert sammenhengen mellom varighet av amming og et knippe sykdommer hos barn som vi mener er relevante i denne sammenhengen: infeksjoner, astma, cøliaki og type 1-diabetes. I disse studiene ble fullamming definert som ernæring med morsmelk uten tillegg av fast føde eller drikke med unntak av vann og vitaminer.

\section{Infeksjoner}

En av de mest konsistente sammenhengene i litteraturen er lavere risiko for infeksjoner blant barn som får morsmelk sammenlignet med de som ikke får. Morsmelkens unike innhold gir beskyttelse mot infeksjoner før barnets eget immunsystem er fullt utviklet. 
I våre data fra Den norske mor og barn-undersøkelsen fant vi ingen støtte for at fullamming ut over fire måneders alder var forbundet med ytterligere redusert risiko for

sykehusinnleggelse grunnet infeksjon. I aldersgruppen o-18 måneder ble 7,3\% av barn som var fullammet i fire måneder innlagt på sykehus for infeksjoner, sammenlignet med 7,7\% når fullamming varte seks måneder eller mer (8).

Funnene stemmer godt overens med sammenlignbare studier (14, 15). I en randomisert studie fra Hviterussland, der intervensjonsgruppen fikk ekstra informasjon om viktigheten av morsmelk, var forekomsten av luftveisinfeksjoner lik, men risikoen for mage/tarminfeksjoner høyere i kontrollgruppen (7). I en ny randomisert studie fra Storbritannia fant man ingen forskjell i forekomst av infeksjoner om barnet fikk annen mat i tillegg til morsmelk fra tre måneders alder sammenlignet med seks måneder (4). I en metaanalyse av observasjonsstudier fra lavinntektsland fant man høyere mortalitet hos barn som ikke ble fullammet de første seks månedene. Det var ikke mulig å sammenligne med fullamming i fire måneder, og det var tatt forbehold om lav studiekvalitet og mangel på informasjon om sammenblandingsfaktorer (16). I land der infeksjoner kan komme fra forurensning i mat, kan slik tilleggsmat være mer risikabel. Kan det være grunn til å gi differensierte råd om spedbarnsernæring etter sykdomspanorama og ressurstilgang $\mathrm{i}$ befolkningen?

Vi har også studert om total ammevarighet, uavhengig av annen føde, er assosiert med infeksjoner de første 18 levemånedene. Vi fant en høyere risiko hos barn som fikk morsmelk mindre enn seks måneder sammenlignet med lengre ammevarighet, men med samme risiko ved ammevarighet i 6-11 som > 12 måneder. Tydeligst var forskjellen for infeksjoner i mage og $\operatorname{tarm}(8)$.

\section{Astma}

I Den norske mor og barn-undersøkelsen fant vi ingen forskjell i risikoen for astma ved sjuårsalderen hos barn som ble fullammet frem til fire måneders alder sammenlignet med seks måneder. Heller ikke episoder med tett pust (hvesing) før tre års alder varierte med varighet av fullamming (17). Total varighet av amming hadde ingen betydning for risikoen for astma ved sju års alder (17).

Våre funn er i tråd med en randomisert studie samt andre prospektive kohortstudier (18-20). En nyere metaanalyse konkluderer med at det ikke finnes assosiasjon mellom varighet av amming og astma (11).

\section{Cøliaki}

Tidspunkt for glutenintroduksjon og mengden gluten i spedbarnskost har vært studert som en mulig risikofaktor for cøliaki. I to observasjonsstudier, inkludert vår egen, var risikoen signifikant lavere når gluten ble introdusert fra 4-5 måneder sammenlignet med seks måneder og senere $(21,22)$. Total varighet av amming hadde ingen betydning for risikoen for senere cøliaki (22).

En randomisert multisenterstudie viste at introduksjon av små mengder gluten fra fire måneders alder sammenlignet med seks måneders alder ga omtrent samme risiko for cøliaki (6). Mengden gluten som ble gitt var svært liten, og intervensjonens relevans er derfor omdiskutert. Metaanalyser spriker i konklusjonene på om glutenintroduksjon fra fire måneder sammenlignet med seks måneder er assosiert med redusert risiko for cøliaki $(23,24)$.

\section{Type 1-diabetes}

Vi har studert data fra den danske fødselskohorten og Den norske mor og barnundersøkelsen med 155000 barn, der 500 barn nå har fått type 1-diabetes. Dette er den største studien i sitt slag. Der fant vi ingen holdepunkter for at varighet av fullamming har 
betydning for risiko for type 1-diabetes (13). Dette er i tråd med en fersk metaanalyse fra ni tidligere kohortstudier som viser at tid for introduksjon av annen mat enn morsmelk ikke er assosiert med risikoen for type 1-diabetes (25).

For type 1-diabetes fant vi ingen sammenheng mellom ammevarighet og sykdom. Vi fant imidlertid at det var $\emptyset \mathrm{kt}$ risiko for type 1-diabetes blant barn som aldri fikk morsmelk. Samtidig må vi ta forbehold om at denne lille gruppen (ca.1\%) kan skille seg ut på andre måter og at det derfor er usikkert om forskjellen skyldes amming alene.

\section{Fødemiddelallergier}

Vi har ikke studert allergier i Den norske mor og barn-undersøkelsen, men randomiserte studier fra de siste årene kan tyde på at introduksjon av allergener før seks måneders alder kan forebygge fødemiddelallergi. Barn med økt allergirisiko som ble randomisert til å unngå peanøtter, hadde langt høyere forekomst av peanøttallergi enn barn som fortsatte med små mengder (5). En annen studie med barn uten økt allergirisiko viste at tidlig innføring av allergener ga lavere risiko for allergi i analysen som inkluderte barn som hadde gjennomført i tråd med studieprotokollen (4). Når alle inkluderte barn ble studert, fant man ingen forskjell i fødemiddelallergier.

I europeiske retningslinjer har man endret anbefalinger om å utsette introduksjon av allergener for å forebygge allergi, og det gjenstår å se om pågående randomiserte studier gir grunnlag for å anbefale tidligere introduksjon av fødemidler (26).

\section{Fire eller seks måneder?}

Våre data utgjør en liten, men viktig del av det totale kunnskapsgrunnlaget som bekrefter at amming er viktig for barnet de første månedene. Samtidig tyder våre funn og andre nyere studier på at fullamming i fire eller seks måneder er likeverdig. Vi har tillit til at helsesøstre og leger informerer godt og balansert om morsmelk som eneste ernæring fra starten, og tror norske mødre fortsatt kan gjøre fornuftige og informerte valg om hvor lenge fullammingen bør vare.

\section{LITTERATUR:}

1. Helsedirektoratet. Nasjonal faglig retningslinje for spedbarnsernæring:

https://helsedirektoratet.no/Retningslinjer/Spedbarnsern\%C3\%A6ring.pdf(5.1.2018).

2. Landaas VØ, Kvammen JA. Svakheter ved Retningslinje for spedbarnsernæring 2016. http://www.ntfe.no/i/2017/1/tfe-2017-01b-1139 (28.2.2018).

3. Helsedirektoratet. Amming og spedbarns kosthold -landsomfattende undersøkelse 2013. https://helsedirektoratet.no/publikasjoner/amming-og-spedbarns-kosthold-landsomfattende-unders okelse-2013 (28.2.2018).

4. Perkin MR, Logan K, Tseng A et al. Randomized Trial of Introduction of Allergenic Foods in BreastFed Infants. N Engl J Med 2016; 374: 1733 - 43. [PubMed][CrossRef]

5. Du Toit G, Roberts G, Sayre PH et al. Randomized trial of peanut consumption in infants at risk for peanut allergy. N Engl J Med 2015; 372: 803-13. [PubMed][CrossRef]

6. Vriezinga SL, Auricchio R, Bravi E et al. Randomized feeding intervention in infants at high risk for celiac disease. N Engl J Med 2014; 371:1304 - 15. [PubMed][CrossRef]

7. Kramer MS, Chalmers B, Hodnett ED et al. Promotion of Breastfeeding Intervention Trial (PROBIT): a randomized trial in the Republic of Belarus. JAMA 2001; 285: 413 - 20. [PubMed][CrossRef]

8. Størdal K, Lundeby KM, Brantsæter AL et al. Breast-feeding and Infant Hospitalization for Infections: Large Cohort and Sibling Analysis. J Pediatr Gastroenterol Nutr 2017; 65: 225 - 31. [PubMed][CrossRef]

9. Victora CG, Bahl R, Barros AJ et al. Breastfeeding in the 21st century: epidemiology, mechanisms, and lifelong effect. Lancet 2016;387: 475 - 90. [PubMed][CrossRef] 
10. Colen CG, Ramey DM. Is breast truly best? Estimating the effects of breastfeeding on long-term child health and wellbeing in the United States using sibling comparisons. Soc Sci Med 2014; 109: 55 65. [PubMed][CrossRef]

11. Lodge CJ, Tan DJ, Lau MX et al. Breastfeeding and asthma and allergies: a systematic review and meta-analysis. Acta Paediatr 2015; 104:38 - 53. [PubMed][CrossRef]

12. Silano M, Agostoni C, Sanz Y et al. Infant feeding and risk of developing celiac disease: a systematic review. BMJ Open 2016; 6: eoog163. [PubMed][CrossRef]

13. Lund-Blix NA, Dydensborg Sander S, Størdal K et al. Infant Feeding and Risk of Type 1 Diabetes in Two Large Scandinavian Birth Cohorts. Diabetes Care 2017; 40: 920 - 7. [PubMed][CrossRef]

14. Quigley MA, Kelly YJ, Sacker A. Infant feeding, solid foods and hospitalisation in the first 8 months after birth. Arch Dis Child 2009; 94: 148 - 50. [PubMed][CrossRef]

15. Duijts L, Jaddoe VW, Hofman A et al. Prolonged and exclusive breastfeeding reduces the risk of infectious diseases in infancy. Pediatrics 2010; 126: e18 - 25. [PubMed][CrossRef]

16. Sankar MJ, Sinha B, Chowdhury R et al. Optimal breastfeeding practices and infant and child mortality: a systematic review and meta-analysis. Acta Paediatr 2015; 104:3 - 13. [PubMed][CrossRef]

17. Lossius AK, Magnus MC, Lunde J et al. Prospective Cohort Study of Breastfeeding and the Risk of Childhood Asthma. J Pediatr 2018; 195:182 - 189.e2. [PubMed][CrossRef]

18. Kramer MS, Matush L, Vanilovich I et al. Effect of prolonged and exclusive breast feeding on risk of allergy and asthma: cluster randomised trial. BM] 2007; 335: 815. [PubMed][CrossRef]

19. Kull I, Melen E, Alm J et al. Breast-feeding in relation to asthma, lung function, and sensitization in young schoolchildren. J Allergy Clin Immunol 2010; 125: 1013 - 9. [PubMed][CrossRef]

20. van Meel ER, de Jong M, Elbert NJ et al. Duration and exclusiveness of breastfeeding and school-age lung function and asthma. Ann Allergy Asthma Immunol 2017; 119: 21 - 26.e2. [PubMed][CrossRef]

21. Norris JM, Barriga K, Hoffenberg EJ et al. Risk of celiac disease autoimmunity and timing of gluten introduction in the diet of infants at increased risk of disease. JAMA 2005; 293: 2343-51.

[PubMed][CrossRef]

22. Størdal K, White RA, Eggesbø M. Early feeding and risk of celiac disease in a prospective birth cohort. Pediatrics 2013; 132: e1202 - 9. [PubMed][CrossRef]

23. Pinto-Sánchez MI, Verdu EF, Liu E et al. Gluten Introduction to Infant Feeding and Risk of Celiac Disease: Systematic Review and Meta-Analysis. J Pediatr 2016; 168: 132 - 43.e3. [PubMed][CrossRef]

24. Szajewska H, Shamir R, Chmielewska A et al. Systematic review with meta-analysis: early infant feeding and coeliac disease-update 2015. Aliment Pharmacol Ther 2015; 41: 1038 - 54. [PubMed][CrossRef]

25. Pieścik-Lech M, Chmielewska A, Shamir R et al. Systematic Review: Early Infant Feeding and the Risk of Type 1 Diabetes. J Pediatr Gastroenterol Nutr 2017; 64: 454 - 9. [PubMed][CrossRef]

26. Muraro A, Halken S, Arshad SH et al. EAACI food allergy and anaphylaxis guidelines. Primary prevention of food allergy. Allergy 2014; 69:590 - 601. [PubMed][CrossRef]

Publisert: 28. mai 2018. Tidsskr Nor Legeforen. DOI: 10.4045/tidsskr.18.0035

Mottatt 5.1.2018, første revisjon innsendt 7.2.2018, godkjent 28.2.2018.

(C) Tidsskrift for Den norske legeforening 2020. Lastet ned fra tidsskriftet.no 